\title{
Response to "Anthropometric Indicators Predict Metabolic Syndrome Diagnosis in Maintenance Hemodialysis Patients: Methodological and Statistical Issues"
}

Volume 31 Number 6

December 2016842

(C) 2016 American Society

for Parenteral and Enteral Nutrition DOI: $10.1177 / 0884533616670373$ ncp.sagepub.com

hosted at

online.sagepub.com
With significant attention and interest, we read the comments by Sani and Ayubi regarding our recent article entitled "Anthropometric Indicators Predict Metabolic Syndrome Diagnosis in Maintenance Hemodialysis Patients." We appreciate the critical analysis of our results and the opportunity to answer it.

We think it is necessary to carefully discuss the issues raised in the letter. We agree accurate predictions cannot be guaranteed with a cross-sectional study. Perhaps the word prediction was not the best choice for the title. However, the meaning of the term prediction is also used with the same intention that we used in other cross-sectional studies, ${ }^{2-4}$ including some articles published in this journal. ${ }^{5,6}$

The area under the receiver operating characteristic (ROC) curve and sensitivity and specificity values were used in this study to quantify the diagnostic ability of the test. ${ }^{7,8}$ In our study, waistto-height ratio is the indicator used to distinguish between 2 diagnostic groups (with and without metabolic syndrome [MetS]).

Stepwise method was chosen because of the collinearity among the variables we wanted to test, which could affect the results of the multivariable logistic regression model to find the best anthropometric index associated with MetS. Beside multivariable logistic regression model, the association between MetS and anthropometric variables was tested using ROC curves. Waist-to-height ratio had the best association with MetS in both analyses. Moreover, the indexes that were best associated with MetS in ROC curve analysis are those that characterize central obesity. These results make sense in the clinical practice, since central obesity, particularly visceral, has been considered the key element in the development of MetS. ${ }^{9}$

Barbara Perez Vogt, RD, MSc

Jacqueline Costa Teixeira Caramori, MD, $\mathrm{PhD}$

Department of Internal Medicine, Faculdade de Medicina de Botucatu, UNESP, Univ Estadual Paulista, Botucatu, São

Paulo Brazil

\section{References}

1. Vogt BP, Ponce D, Caramori JCT. Anthropometric indicators predict metabolic syndrome diagnosis in maintenance hemodialysis patients. Nutr Clin Pract. 2016;31:368-374.

2. Liu Y, Tong G, Tong W, Lu L, Qin X. Can body mass index, waist circumference, waist-hip ratio and waist-height ratio predict the presence of multiple metabolic risk factors in Chinese subjects? BMC Public Health. 2011;11:35.

3. Ho S-Y, Lam T-H, Janus ED. Waist to stature ratio is more strongly associated with cardiovascular risk factors than other simple anthropometric indices. Ann Epidemiol. 2003;13:683-691.

4. Koutsovasilis A, Protopsaltis J, Triposkiadis F, et al. Comparative performance of three metabolic syndrome definitions in the prediction of acute coronary syndrome. Inter Med. 2009;48:179-187.

5. Genaro PS, Pinheiro MM, Szejnfeld VL, Martini LA. Dietary protein intake in elderly women: association with muscle and bone mass. Nutr Clin Pract. 2015;30:283-289.

6. Gouveri ET, Tzavara C, Drakopanagiotakis F, et al. Mediterranean diet and metabolic syndrome in an urban population: the Athens Study. Nutr Clin Pract. 2011;26:598-606.

7. Altman DG, Bland JM. Diagnostic tests 1 : sensitivity and specificity. $\mathrm{Br}$ Med J. 1994;308:1552.

8. Altman DG, Bland JM. Diagnostic tests 3: receiver operating characteristics plots. Br Med J. 1994;309:188.

9. Alberti G. Introduction to the metabolic syndrome. Eur Heart J Suppl. 2005;7:D3-D5

Financial disclosure: A master's degree scholarship was provided to B. P. Vogt by Coordination of Improvement of Higher Education Personnel (Coordenação de Aperfeiçoamento de Pessoal de Nível Superior), an organization of the Brazilian federal government under the Ministry of Education. 